\title{
Neurosurgery at the Toronto General Hospital, 1924 - 1990: Part 2
}

\author{
J. Max Findlay
}

Part 1 of this two part series outlined the beginning of Canadian neurosurgery and neurosurgical training at the Toronto General Hospital under Kenneth G. McKenzie, and described the efforts of E. Harry Botterell, McKenzie's neurosurgical trainee and successor, in establishing the Toronto school of neurosurgery. ${ }^{1}$ This second part reviews the course of neurosurgery at the Toronto General until the creation of The Toronto Hospital.

\section{Thomas Paterson Morley and Neurosurgery at the Toronto} General Hospital, 1962-1979

\section{Neurosurgical training under Sir Geoffrey Jefferson}

Thomas P. Morley was born in Manchester, England, on June 13, 1920. His father, a general surgeon, was Professor of Surgery at the University of Manchester. Morley attended University College at Oxford, obtaining a B.A. degree in 1940 and B.M. and B.Ch. degrees in 1943. Following graduation, and a brief appointment as a resident medical officer at a large private lunatic asylum outside Manchester (where included among his duties was administration of insulin shock therapy, remembered as a distressing practice for everyone involved), Morley spent six months as house Surgeon (the British equivalent of an intern) to Professor Geoffrey Jefferson. The original attraction to this job was a practical one: it was the only housesurgeon position vacant and available. Starting out, young Morley had not wanted to become a neurosurgeon, but even this short exposure to the keenly intelligent and fascinating mind of Geoffrey Jefferson convinced him that he could be nothing else.

In the midst of World War II Morley entered the Royal Air Force, serving as a squadron medical officer first in England and then India for two years. Following demobilization in 1946 he worked briefly as a family doctor, followed by training in orthopedic and general surgery. Obtaining his Royal College of Surgeons (England) Fellowship in 1948, he was then able to return to Jefferson for neurosurgical training.

The articulate, intellectual, and philosophical Sir Geoffrey Jefferson had a profound influence on Morley, and in turn, influenced neurosurgery at the Toronto General Hospital. Dr. Morley spent three and one-half years training with Jefferson, and many years later paid a fond tribute to his neurosurgical mentor. ${ }^{2}$

At completion of Morley's residency the outlook for a staff appointment in neurosurgery in England looked bleak. When Dr. Botterell succeeded McKenzie as Chief of Neurosurgery at Toronto General Hospital in 1952 it was decided that a third neurosurgeon was needed on the service. Having established close ties with Manchester and Sir Geoffrey Jefferson during the war, Botterell canvassed Jefferson's senior registrars. As a result, Morley flew to Canada, and his introductory several days in Toronto concluded with a somber interview in the then
Professor of Surgery Robert Janes' office in the Banting Institute. As Morley recalls it, Prof. Janes began: "Well Morley, thank you for coming, it was a joy having you here, and we would like to offer you a probationary one-year appointment." Morley responded that that seemed fair, and if either he was not satisfactory or happy in Toronto then he could be released from further obligation. "No," answered Prof. Janes, "if you are satisfactory to us, and if you say you are unhappy here for whatever reason, you will still stay." Not wanting the opportunity to slip through his fingers, Morley quickly thanked Prof. Janes for making clear the very reasonable conditions of the offer he was happy to accept.

\section{Thomas P. Morley at the Toronto General Hospital}

Dr. Morley moved to Canada in 1952 and after spending a year as fellow on the neurosurgical service at Toronto General Hospital obtained both his Canadian Royal College Fellowship in Neurosurgery and a junior staff appointment. He quickly established himself as an astute clinician and skilled surgeon. Morley also opened Toronto's first neurosurgical research laboratory in 1953, growing brain tumor cell cultures in a small borrowed room at the Banting Institute. The laboratory expanded, and 16 years later, in 1969, was eventually taken over by one of Morley's Ph.D. graduates, Dr. Charles Tator.

In 1962, when Harry Botterell accepted the position of Dean of Medicine at Queen's University, Morley succeeded him as Head of the division of Neurosurgery at the Toronto General Hospital, and in 1964 he was named Chairman of Neurosurgery at the University of Toronto (Figure 1). Although possessed of a calmer, more aristocratic demeanour than Dr. Botterell, Morley became no less the "Professor". One now senior neurosurgeon recalls spending several months on the neurosurgical service at Toronto General Hospital as a keen young intern anxious to be accepted to neurosurgical training. He worked hard and late every day and weekend, and hoping to make an impression, paid particular attention to Dr. Morley's admissions. On the last day of this exhausting rotation the chief resident suggested that the time was right for the intern to pay a visit to Dr. Morley for an interview. The intern was ushered quietly into Morley's office. Dr. Morley sat at his desk, pen in hand, and peering up over his reading glasses at the applicant, began the interview. "Name?", he inquired.

From the Division of Neurosurgery, University of Alberta, Edmonton.

RECEIVED APRIL 15, 1993. ACCEPTED IN FINAL FORM OCTOBER 29, 1993.

Reprint requests to: J. Max Findlay, MD, University of Alberta, Department of Surgery, 2D1.02 Mackenzie Health Sciences Centre, 8440 - 112 Street, Edmonton, Alberta, Canada T6G 2B7 


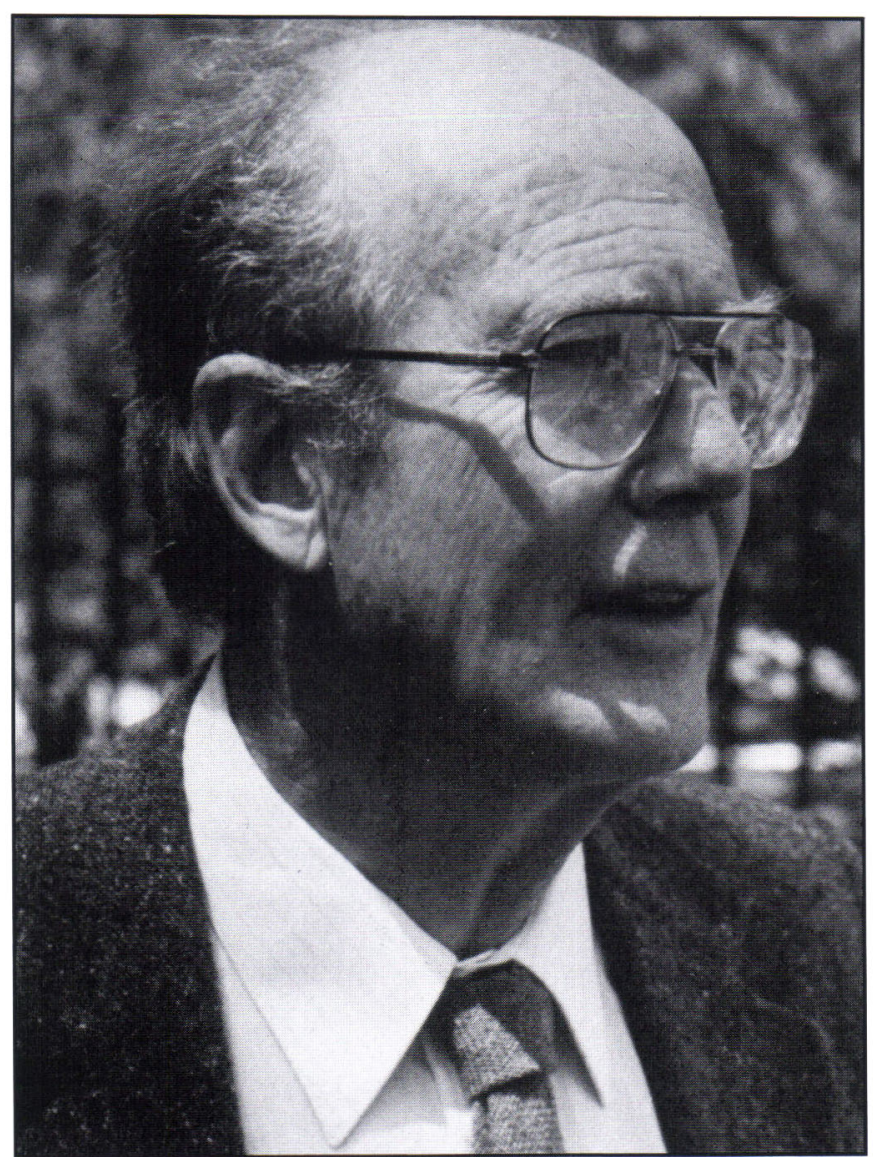

Figure 1. Dr. Thomas P. Morley, Toronto (Summer of 1992).

One of Morley's achievements as Chairman of Neurosurgery in Toronto was expanding the training program, beginning with the acceptance of additional residents so that two would complete training the same year. One of his priorities was maintaining the high quality of the training program established by his predecessors, and he paid particular attention to the resident selection process. Morley avoided a paternalistic attitude towards his trainees and younger colleagues at the University of Toronto. $\mathrm{He}$ expected them, as mature individuals, to learn and perform excellent neurosurgery, pursue a research interest and become productive with his assistance and encouragement, but without structured interference or enforcement. His guiding principle, in his own words, was that if you "picked a man, the right man, you should leave him alone, not breathe down his neck, and let him get on with his job and develop in the way he himself felt fruitful."

Like Drs. McKenzie and Botterell before him, Morley supported the creation and strengthening of neurosurgical divisions at other major Toronto hospitals. He helped form a neurosurgical unit at the Wellesley Hospital in 1968 and recruited Dr. Kenneth Livingston to head that new division. In 1974 and independent Division of Neurosurgery was established at the Sunnybrook Medical Center when Charles Tator was appointed head.

While neurosurgery was growing elsewhere in the city, at the Toronto General Hospital Morley recognized the importance of another of Dr. Botterell's strategies, and that was subspecialization within his own division. Dr. Morley's own research endeavours were in the study of brain tumors, and on the clinical side he achieved particular distinction as a tumor surgeon. His residents remember his Henry Birk's silver teaspoons, with holes drilled through the bowls to both render them unattractive to thieves and to allow their gathering on a large bobby-pin for autoclaving. He found these spoons useful for scooping out gliomas and occasionally as retractors. His residents also remember his careful and wise judgment in managing meningiomas, and his fluent, rapid and assured operating technique.

Dr. Morley also maintained a constant interest in tic douloureux. While he enjoyed the accuracy, selectivity and reliability of the Frazier operation (which he also thought was good training for cavernous sinus surgery of any sort), he really preferred more "minimal" operations for tic (either percutaneous or open peripheral rhizotomy). ${ }^{3}$ In later years he watched, with some concern, the growing popularity of posterior fossa microvascular decompression. ${ }^{4}$ Morley also made valuable contributions in vascular neurosurgery, including the first definition and characterization of "giant" intracranial aneurysms, ${ }^{5}$ and along with Hugenholtz a detailed analysis of the results of a once popular and still occasionally justifiable treatment for anterior communicating artery aneurysms: proximal anterior cerebral artery occlusion. ${ }^{6}$ Another important report pointed out the possibility of post-traumatic dural fistulae and cerebrospinal fluid leakage from lateral extensions of the sphenoid sinus. ${ }^{7}$ Perhaps Morley's most outstanding contribution to the neurosurgical literature was his book Current Controversies in Neurosurgery, published $1976 .{ }^{8}$ In this book concise chapters on a large number of evolving neurosurgical subjects, written by experts in their respective fields, are woven together and enhanced by brief, articulate and penetrating commentaries by the editor. Morley has also written on professional and historical aspects of Canadian neurosurgery. ${ }^{9.10} \mathrm{Dr}$. Morley's colleagues at the Toronto General Hospital became preeminent in other areas of neurosurgery.

\section{William M. Lougheed and cerebrovascular surgery at Toronto General Hospital}

Dr. Bill Lougheed joined the Toronto General Hospital surgical staff in 1956 and opened a cerebrovascular research laboratory at the Banting Institute." Recognizing the advantages of the microscope in surgery, in the early 1960's he began a series of experiments in microvascular reconstruction. ${ }^{12-14}$ The development of a maneuverable, double-headed surgical diploscope enable Lougheed to become one of the world's first, and Canada's first, microneurosurgeon.

In 1969 Lougheed and neuroanesthetist Brian Marshall reported a series of 40 patients with ruptured aneurysms repaired with the operating diploscope and Lougheed-Kerr aneurysm clips, ${ }^{15,16}$ one of the largest series of microsurgically operated aneurysms at that time.

Lougheed performed the first successful cerebral long-vein bypass procedure in the world in $1971 . .^{17} \mathrm{He}$ became interested in reconstruction of the stenosed carotid artery very early in his career, and in 1966 along with Robert Elgie and neurological colleague Henry Barnett, reported on the first 109 patients undergoing endarterectomy for carotid artery occlusion or 
stenosis at the Toronto General Hospital, the first large series of carotid endarterectomies in Canada..$^{18}$

Combined with his earlier work in hypothermia in neurosurgery, Lougheed played a major role in putting Toronto General Hospital "on the map" in cerebrovascular neurosurgery. Of equal importance was Lougheed's contribution to the training of neurosurgical residents. He was unrivalled as a "gloveson" teacher of operative neurosurgery. ${ }^{19}$

\section{Ronald $\boldsymbol{R}$. Tasker and stereotactic neurosurgery at the Toronto General Hospital}

Dr. Tasker joined the staff of the hospital in 1961 and focused his research and clinical efforts on stereotactic neurosurgery (Figure 2). Since this was approximately six years prior to the general availability of L-dopa, stereotactic functional neurosurgery was in its heyday, and Tasker was initially referred a great number of patients with Parkinson's disease. Along with these patients came those with other types of movement disorders, chronic pain or epilepsy. Tasker also became associated with the newly opened Eleanor Smythe Pain Clinic, initially seeing mainly patients from the Princess Margaret Hospital with cancer-related pain. It was then that he first became interested in percutaneous cordotomy, a technique that he subsequently helped popularize. ${ }^{20}$ One of Tasker's main contributions to functional neurosurgery has been his effort, through microelectrode stimulation and recording to understand the physiology of the conditions he has treated, such as the movement disorders and chronic pain, and in so doing develop more selective and effective therapies. A major accomplishment was his book, The Thalamus and Midbrain of Man, published in $1982,{ }^{21}$ which is a unique atlas combining anatomic and physiologic information.

Although the popularity and clinical application of stereotactic techniques has varied over the years, Dr. Tasker's devotion to this branch of neurosurgery has not. He has steadfastly

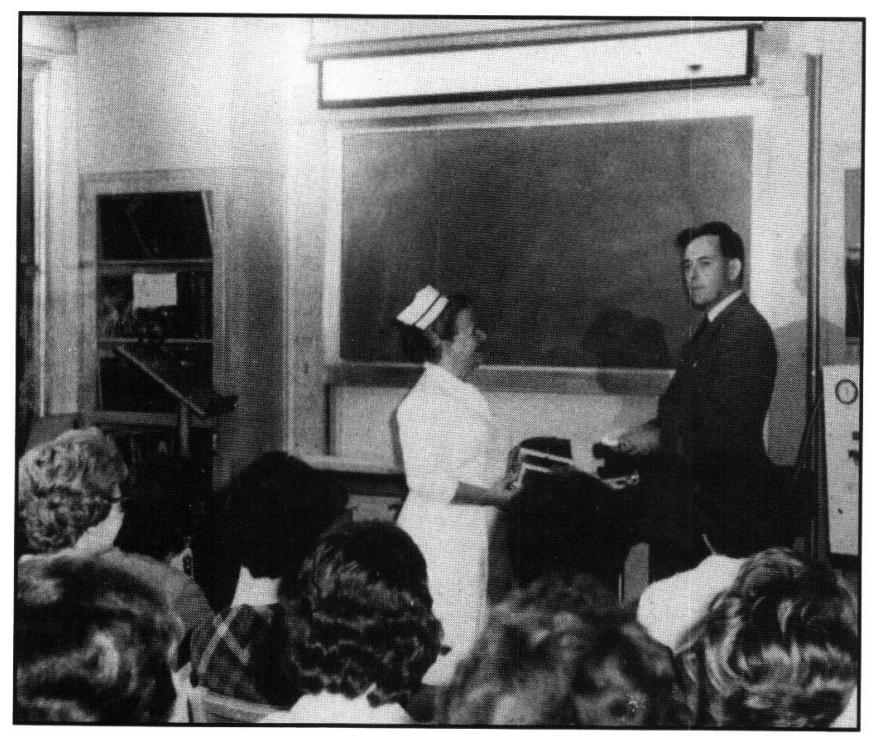

Figure 2. Dr. Ron Tasker and Jessie Young R.N., demonstrating a stereotactic frame to a neurosurgical nursing class, circa late 1960's. Photograph courtesy of Jessie Young. brought his considerable intellectual powers and meticulous observational skills to bear on the problems of functional neurosurgery for over two decades now, and has become one of the world leaders in his field.

\section{Resident training at the Toronto General Hospital under T.P. Morley: neurology, neuropathology and the residents}

During Morley's tenure as Chairman of Neurosurgery in Toronto, neurology and neuropathology continued to play an important role in resident teaching at the Toronto General Hospital. With the retirement of Hyland in 1960 J.C. Richardson became Head of the Division of Neurology, ${ }^{22}$ and it was about this same time that the Royal College began to require neurosurgery residents take six months training in neurology. Most neurosurgical residents spent at least several of these months under Richardson's direct supervision. In the absence of computerized tomographic scans in the 1960's and 70 's clinical assessment was of much greater importance than is the case today, and Dr. Richardson took particular interest in teaching neurosurgical residents the skills of classical neurology and lesion localization through meticulous history taking a physical examination.

Another neurologist who had important clinical ties to neurosurgery and who helped train a succession of neurosurgical residents at Toronto General Hospital was Dr. H.J. Barnett. Henry Barnett trained in neurology in Toronto, Queen Square and Oxford before joining the medical staff at the Toronto General Hospital in 1952. One of the skills he acquired in England was cerebral angiography, and performing angiograms at the Toronto General Hospital, uncovering cerebral aneurysms and obstructive carotid lesions, he developed a particular interest in cerebrovascular disease. He recognized the potential merit of surgery for these problems, and was the first to submit patients for the newly conceived procedure carotid endarterectomy. Close ties were established between Henry Barnett and Bill Lougheed and the two even attempted to carry out a randomized study of carotid endarterectomy versus anticoagulation soon after introduction of endarterectomy of Toronto General Hospital. However, this early attempt at scientifically validating a new treatment, which placed Barnett decades ahead of his time, in the late 1950 's, was quickly thwarted when senior colleagues deemed the trial unethical.

Besides his major interest in stroke an cerebrovascular disease another of Barnett's major contributions he made along with Albin Jousse, was the recognition and description of posttraumatic syringomyelia. ${ }^{23}$ Jousse, who examined and kept very close track of the paraplegic patients he had treated at Lyndhurst Lodge, began noting that occasional patients would deteriorate in a delayed fashion, sometimes years after the accident, with progressive upper extremity involvement. He had Barnett see these patients, who in turn recognized that they had syringomyelia. The first operations for post-traumatic syringomyelia were done at the Toronto General Hospital, and the very first one was itself a bold but successful procedure (performed by Dr. Morley): a thoracic cordectomy and syrinx decompression into the subarachnoid space below the level of injury.

Dr. Barnett moved to Sunnybrook Hospital in 1967 to create a Division of Neurology, and his dream of creating a comprehensive Department of Clinical Neurological Sciences was realized after 1969 when he was recruited to the University of 
Western Ontario to join his friend and surgical counterpart, Charles Drake.

Professor of Neuropathology Eric Linell retired from his university position in 1957, and Mary Tom became acting head. Though she was offered the headship of the division, she declined, and in 1959 Jerzy Olszewski, a Polish-trained neuroanatomist who had worked at the Montreal Neurological Institute after World War II, was recruited from Saskatoon and appointed Professor and Head in the Division of Neuropathology at the University of Toronto (Figure 3). ${ }^{24}$ Professor Olszewski, a charismatic and mesmerizing teacher, also collaborated with research in Morley's brain tumor laboratory. Olszewski taught neuropathology to a succession of neurosurgery residents. Upon Prof. Olszewski's sudden death in 1964, Mary Tom once again became acting Head, but Dr. N.B. Rewcastle was summoned home prematurely from a fellowship in Germany. In 1965 Mary Tom retired from her position and Barry Rewcastle was appointed acting head of the Division of Neuropathology, University of Toronto, and senior pathologist at the Toronto General Hospital. Five years later he was named Professor and Head of the University Division. From 1965 until 1981, when he became Head of Pathology at the University of Calgary, Prof. Rewcastle trained several generations of neurosurgeons and neurologists in neuropathology at the Toronto General Hospital. He insisted the neurosurgical residents spend a full year with him, believing in part that he "couldn't get much out of them until they had spent six months on the service", but mainly that it was very difficult for a neurosurgical resident to orientate themselves in neuropathology, identify an intellectual problem, address it in a scientific fashion and produce a paper in less than twelve months. He is remembered by these residents as a superb and tireless teacher. Dr. John Deck, who had trained in Toronto and then at Stanford with Professor Lucien Rubinstein, moved from the Toronto Western Hospital to Toronto General in 1982 to fill Rewcastle's position.

Another development that had a positive influence on neurosurgical training at Toronto General Hospital in the late 1970's

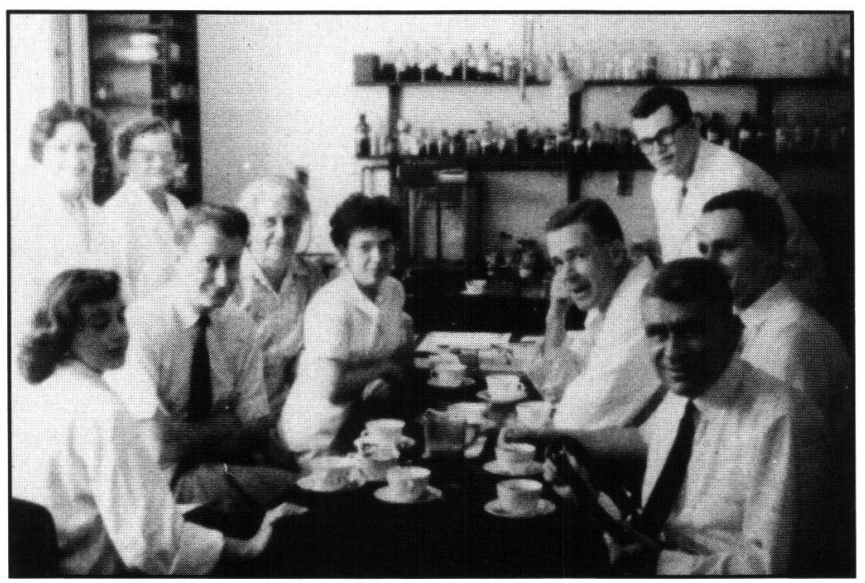

Figure 3. Neuropathology laboratory at the Banting Institute, circa early 1960's. Dr. Barry Rewcastle is seated on the lefi of the table, and seated behind him is Dr. Mary Tom. Seated on the right, from front to back, are Professor Jerzy Olszewski, Dr. Harold Hoffman and Dr. Robert McPhedran. The other persons are the technical staff. Photograph courtesy of Dr. Barry Rewcastle. was Dr. I.B. Schacter's association with the Toronto General Unit. Dr. Schacter, who had trained in neurosurgery with Professor Jefferson Browder at the Down State Medical Center, State University of New York, maintained his firm affiliation with the Mount Sinai Hospital in Toronto, but began at that time sending some of his cranial cases to the Toronto General for surgery. While he acquired some valuable resident assistance for these cases, the residents in return became exposed to a larger volume of interesting pathology.

A total of 50 neurosurgeons finished either all or a significant part of their neurosurgical training at the University of Toronto while Morley was Chairman, and many have achieved national and international distinction. A number of these surgeons have remained with the University of Toronto and risen to local prominence as well.

Dr. Harold J. Hoffman spent six months as Chief Resident under Botterell, and upon Botterell's departure for Queen's in 1962, one year under Morley. Following a McLaughlin Fellowship in England he was recruited to the Hospital for Sick Children in 1964. In 1970 a clinical fellowship program in paediatric neurosurgery was established and a year later Robin Humphreys was recruited from the Toronto program to join the staff. The trio of Drs. Hendrick, Hoffman and Humphreys rapidly established one of the world's most outstanding paediatric neurosurgical units, drawing both patients and clinical fellows from around the world. Dr. Hoffman, who has made numerous key clinical contributions to paediatric brain tumor management, as well as to almost every other aspect of paediatric neurosurgery, has also been a prominent member of numerous international neurosurgical organizations and Chief of Neurosurgery at the Hospital for Sick Children since 1986.

Dr. Alan R. Hudson graduated from medical school in his homeland, at the University of Capetown, in 1960. He then followed a fellow university student, with whom he had fallen in love, back to Canada in 1962 where he had been fortunate enough to land a six month job studying head injuries in children with Bruce Hendrick. He then moved to London, England, where he became a general surgeon, obtaining his Edinburgh Fellowship in 1964 at age 24. Wishing to return with his Canadian wife to Canada, he wrote to Hendrick enquiring if there were any jobs available, meaning, but not explicitly stating, in general surgery. Dr. Hendrick responded with a telegram congratulating Hudson on successfully obtaining a position in the Toronto neurosurgery training program! With considerable uncertainty Hudson accepted. Although Dr. Morley was prepared to fire Hudson before he started, since he had calculated that Hudson was a few days late arriving from overseas, he quickly found the young Dr. Hudson "the answer to every program directors dreams, a talented and hard-working resident who ran the show (service) completely, and sometimes ruthlessly - a talent he was able to refine later in life."

Hudson spent much of his training, including his Chief Resident year, with Bill Horsey at St. Michael's Hospital. His superb knowledge of gross anatomy, resulting in part from his general surgical background, interested him in peripheral nerve problems and surgery. Following his neurosurgery exams he served a year with Professor G. Weddell in Oxford as a McLaughlin Fellow studying peripheral nerve regeneration, and he brought this research interest back to St. Michael's Hospital in 1970 when he joined the surgical staff there. In addition to 
pursuing basic laboratory studies on peripheral nerve injury and repair, Hudson has become one of the world experts on major peripheral nerve reconstructive surgery. Dr. Hudson succeeded Horsey as St. Michael's Neurosurgeon-in-Chief in 1977, and in 1979 was named Professor and Chairman of Neurosurgery at the University of Toronto, a position he excelled in until 1989, when his term expired. In 1989 he was named Surgeon-in-Chief to The Toronto Hospital, and in 1991 he obtained the appointment of President and Chief Executive Officer of the same institution.

Dr. Charles H. Tator, a native Torontonian, finished medical school at the University of Toronto, silver medallist, in 1961. A liking of neuroscience and neuroanatomy led him into neurosurgery, and he was the last resident accepted into the program by Botterell. He pursued brain tumor research in Dr. Morley's laboratory from 1962 until 1965, finishing with a Ph.D. He then did his clinical neurosurgical training, finishing in 1969. Tator's interest in spinal cord injury began in his internship year at the Toronto General Hospital in 1961-62, during which time he assisted Dr. D.W. Gordon Murray with one of his "spinal cord reanastomosis" procedures. ${ }^{25}$ The kindling of Tator's interest in spinal cord injury was the one very good thing that came out of an incident that unfortunately, otherwise, only stained the fading career of an imaginative and brilliant Canadian surgeon, Dr. Gordon Murray.

Several years after starting a full-time neurosurgical practice at Sunnybrook Medical Center and simultaneously running Morley's former laboratory in the Banting Institute, and then the Medical Sciences Building at the University of Toronto, Tator decided that it was not possible for him to maintain two serious research programs, and by the late 1970's he had largely put aside his substantial brain tumor research efforts and concentrated exclusively on spinal cord injury. At the time the study of spinal cord injury was more appealing, seeming closer to a solution than the enormous problem of glioblastoma multiforme (not unlike Botterell's thoughts several decades prior!). An excellent rat model was established for the laboratory, and on the clinical side in 1974 Tator established the Acute Spinal Cord Injury Unit at Sunnybrook Medical Center, the first such unit in Canada. Both Dr. Tator's laboratory and clinical efforts to better understand, treat and prevent spinal cord injuries have been innovative and successful, and he has achieved preeminence in this field. In addition, a succession of neurosurgical residents have passed through his laboratory on graduate degree programs. Dr. Tator has also accumulated an enormous clinical experience in his other field of interest, the surgery of acoustic schwannoma.

Dr. Hart Schutz was enrolled in the Gallie Course as an orthopedic resident when he rotated through neurosurgery and fell under the spell of Dr. Bill Lougheed and the pioneering work in microneurosurgery being done at the Toronto General Hospital. He made the conversion into a neurosurgical trainee, and before completing his residency under Morley in 1970 had already developed the opinion that neurosurgical patients could be better monitored with invasive intracranial pressure and cerebral blood flow monitoring. He travelled on a McLaughlin Fellowship to Europe for six months, working longest with Professor Siesjo in Lund, Sweden on the effect of intracranial pressure on brain energy metabolism. Schutz then spent a year in Professor Langfitt's laboratory in Philadelphia studying intracranial pressure and mitochondrial function. One of Schutz's first contributions when he returned to join the staff at Toronto Western Hospital in 1972 was to introduce and champion the concept and technique of intracranial pressure monitoring. Xenon cerebral blood flow measurements, which he undertook more occasionally, proved technically too difficult for useful or routine clinical application. He maintained his interest in microsurgery, and his early, large experience in cerebrovascular bypass surgery resulted in his appointments as the Toronto surgical study coordinator and principal surgeon for the International EC-IC Bypass study (1977-1985). In 1980 he established the William M. Lougheed Microneurosurgical Teaching Laboratory at Toronto Western Hospital. He was also one of the first, if not the first, Toronto neurosurgeon to perform microsurgical discectomies, his interest in the procedure dating back to 1975 .

While Schutz had held the position as attending neurosurgeon at the Mississauga General Hospital since 1972, in 1987 he left active practice at the Toronto Western Hospital to start his own, new division of neurosurgery at the Mississauga hospital.

Dr. Paul J. Muller finished his neurosurgical training in 1975 and then spent two years in brain tumor research in Tator's laboratory. Muller pursued this interest in neuro-oncology after taking a staff position at the Calgary General Hospital in 1977, studying "superfractionated" (more, smaller doses of radiation) radiotherapy in a mouse brain tumor model at the University of Calgary. This work soon translated into a trial in patients with glioma, but in time Muller's critical assessment was that different ways of administrating radiotherapy were equally beneficial.

In 1982 Muller was recruited back to Toronto to become the Head of the St. Michael's Hospital Division of Neurosurgery, and shortly thereafter he joined forces with a basic scientist, Dr. Brian Wilson, to study photodynamic therapy of brain tumors. In 1992 he was named Surgeon-in-Chief of St. Michael's Hospital.

After interning at Toronto General Hospital Dr. Fred Gentili worked for two years in Ron Tasker's laboratory, obtaining a M.Sc. studying the effect of stereotaxic dentatectomy in animal models of spasticity. After completing his neurosurgical residency in 1980 he studied peripheral nerve with Alan Hudson for six months, and then spent a valuable year in Europe, serving six months as a Clinical Fellow in Microsurgery with Professor Yasargil at the Kanton Hospital in Zurich, and six months as a Clinical Fellow in Cerebrovascular Surgery with Professor Symon at Queen Square. When he joined the division of neurosurgery at Toronto General Hospital in 1982 he introduced Prof. Yasargil's high level, and broad application of microsurgery to his clinical practice, and from Queen Square he brought the new technique of intraoperative somatosensory evoked potential monitoring. While most of his research efforts have been in the field of cerebrovascular surgery, Dr. Gentili has maintained a keen interest in all aspects of technical and operative neurosurgery.

Friendly, urbane, and gentlemanly, Dr. Morley is fondly remembered by all of his former residents. Morley retired from neurosurgery in 1985, and in 1986 the Morley Neurosurgical resident Prize, an annual award honouring Dr. Morley's achievements in stimulating research within the Division, was established. 


\section{The Playfair Neuroscience Unit}

A significant decision made in the mid 1970's, was to build the Playfair Neuroscience Unit at the Toronto Western Hospital. Mr. Stuart Playfair, a wealthy financier, had endowed the University of Toronto with a large amount of stock in the Tampax company, producers of the popular sanitary napkin, almost two decades prior, to be used in Parkinson's disease and neuroscience research. He made this large donation in memory of his wife, Mrs. Helen Scott Playfair, who suffered with Parkinson's disease for the latter part of her life. The Playfair fund was administered by a committee, and for about ten years only small grants were made from the dividends derived from the Tampax stock. As time passed the Playfair family expressed an interest in seeing something more tangible come of their endowment, which had grown to over seven million dollars, perhaps consisting of bricks and mortar, but there was also great concern about the market price of the stock should it all be sold to finance such an enterprise. A number of individuals at the Toronto General Hospital at various times had supported the idea of development of a neurosciences institute affiliated with the University and Toronto General Hospital. It was Mr. Playfair's intent that his original endowment be spent, and about 1972 a grandson went to the President of the University of Toronto, Dr. John Evans, and demanded his grandfather's wishes be adhered to. A committee was therefore struck, chaired by Dr. Hollenberg, Professor of Medicine, that recommended the creation of laboratories and salaried positions for investigators. The Dean of Medicine, Dr. Laurie Chute, called for submissions from the teaching hospitals, since it had been decided that the investigative unit would be at a hospital rather than out of the main university campus. The Toronto Western was selected, winning out over a combined Toronto General, Sick Children's Hospitals bid. Although this decision may have reflected a desire to spread academia beyond the Toronto General Hospital, the Toronto Western Hospital had already a very strong neuroscience program, and its Chairman of the Board Mr. Trevor Moore along with Drs. Ross Fleming, Jack Silversides and Bill McIlroy made a very determined bid to have the Playfair Unit built at their hospital. Unfortunately, by the time the planning for the new unit was complete and a Director chosen, the patent on Tampax expired and the value of the still unsold stock decreased to about three million dollars. The Playfair Neurosciences Unit was officially opened at the Toronto Western Hospital in 1978, and its presence there would ultimately bear significantly upon the future of neurosurgery at the Toronto General Hospital.

\section{Later Developments in Neurosurgery at the Toronto General Hospital, 1979-1989}

In 1979 Dr. Morley stepped down as Chairman of the Neurosurgical Committee at the University of Toronto and was replaced by Dr. Alan Hudson, Head of Neurosurgery at St. Michael's Hospital, Toronto. That same year Dr. Tasker succeeded Morley as Divisional Head at the Toronto General Hospital. Several years later the neurosurgical service was transferred from the Norman Urquhart wing to the seventh floor of the new Eaton Building, and while the new ward was modern and air conditioned, it contained fewer neurosurgical patient beds. This was the first of many cutbacks, reductions and closures that Tasker resisted but ended up having to contend with over the ensuing years.
It was inevitable, in the decade that followed, that with new Chairman, and many other talented neurosurgeons, located at other strong university-affiliated neurosurgical units in Toronto, the relative strength of the division of Toronto General Hospital would diminish, compared to years past. As perhaps a natural consequence of a process initiated by McKenzie and Botterell, the traditional power-base of neurosurgery at the Toronto General Hospital shrank with greater divisional communication and democracy, and recognition that each division was as much "the University" as the Toronto General.

When Charles Tator was appointed Head of the Division of Neurosurgery at Toronto Western Hospital in 1985, succeeding the capable Ross Fleming, he expanded and strengthened the Playfair Neuroscience Unit with his successful research laboratory, and his presence. With Tator's move from Sunnybrook Hospital the Toronto Western Neurosurgical Division grew to the largest in the city, with five full-time neurosurgeons. In 1989 Tator was also appointed Chairman of the Division of neurosurgery at the University of Toronto, replacing Alan Hudson who had served ten years in that position. Badly needed political strength, and additional neurosurgical manpower, for the Toronto General Hospital Division came in the form of Dr. Hudson himself when he was appointed Surgeon-in-Chief at The Toronto Hospital in 1989. However, by this time it had been three years since the Toronto General and Toronto Western Hospitals had merged administratively, and a year since the neurosurgical divisions at the two hospitals had joined, forming one group practice, with Dr. Tator appointed Head of the newly created Division of Neurosurgery at The Toronto Hospital, the name given to the merged hospital. After much discussion it had become clear that a physical consolidation of the two units was necessary and in the best interest of patient care and academic excellence. Eventually, a combination of administrative force, a separate decision to have cardiac surgery at the General Hospital site, and the trauma service at the Western site, and the

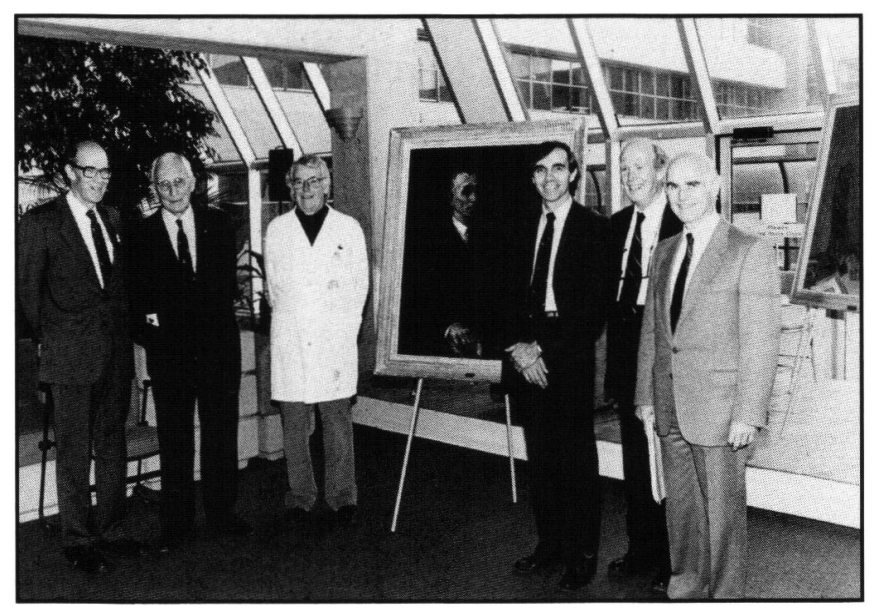

Figure 4. The official opening of the Neurosurgical Unit of the Tornto Hospital at the Toronto Western Hospital site, November 15, 1990. Present in this photograph, from left to right are Drs. Ross Fleming, Harry Botterell, Ron Tasker, Fred Gentili. Tom Morley and Charles Tator. In the background are the Botterell and McKenzie portraits, which have been moved to hang on the Botterell and McKenzie Service wards, respectively, of the new unit. 
sensibility of having the combined neurosurgical unit attached to the well-established Playfair Neuroscience Unit rather than the costly alternative of moving this unit to Toronto General, prevailed, and in June 1990 the new combined Toronto Hospital Neurosurgical Division was opened at the Toronto Western Division $^{26}$ (Figure 4).

The unavoidable sadness that came with moving the neurosurgical service from the physical birthplace of neurosurgery in Canada, the Toronto General Hospital itself, was offset by the excitement in creating of one of the largest neuroscience clinical and investigative units in North America. The Division of Neurosurgery became the largest in Canada, with 10 full-time neurosurgeons, 96 neurosurgical beds and three neurosurgical operating theatres. The consolidation of neurosurgery and neurology at The Toronto Hospital has provided neuroscience resources that considerably exceed the sum of the previously separate hospitals. The names McKenzie and Botterell live on in the merged unit, the wards having been divided into the "McKenzie Service", which focuses on tumor, functional stereotactic and spinal problems, and the "Botterell Service", which concentrates on cerebrovascular disease. The portraits of McKenzie and Botterell have been relocated to a central position in their respective clinical units. Ross Fleming's central role in building the neurosurgical unit at The Toronto Hospital has been recognized by naming the new neuro-intensive care unit the "Fleming Neurosurgical Intensive Care Unit".

Canada's pioneer neurosurgeon, K.G. McKenzie, was himself always prepared for this type of progress, development and change, as he indicated in his address on the occasion of the long-ago opening of another, "new" Neurosurgical Unit in 1958:27

"Let it be kept in mind, however, that a new era is always in the offing; nothing is ever quite finished. How dull life would become if changes and progress should cease!"

\section{ACKNOWLEDGEMENTS}

This work would not have been possible without the support of the author's neurosurgical associates in Edmonton. It is noteworthy that most of the persons whom this essay is about contributed generously with their time, memories and advice. Special help was received from Frank Turnbull (Vancouver), Harry Botterell (Kingston), Bill Stevenson (Stuart, Florida), Charles Taylor (Calgary), Henry Barnett (London), Bill Lougheed (Barrie), Ross Fleming (Toronto), John Wherrett (Toronto), Barry Rewcastle (Calgary), Charles Tator (Toronto) and Bill Tucker (Toronto). Although each provided valuable editorial assistance, all of the mistakes are my own. Mrs. Laurie Arneson accurately transcribed two dozen poorly recorded interviews as well as numerous revisions of this manuscript, and I am very grateful for her talented assistance.

\section{REFERENCES}

1. Findlay JM. Neurosurgery at the Toronto General Hospital, 1924 1990: Part 1. Can J Neurol Sci 1994; 21 : 146-158.

2. Morley TP. Obituary - Sir Geoffrey Jefferson. Acta Neurochir (Wien) 1961; 9: 718-723

3. Morley TP. The place of peripheral and subtemporal ablative operations in the treatment of trigeminal neuralgia (tic douloureux). Clin Neurosurg 1977; 24: 550-556.
4. Morley TP. Case against microvascular decompression in the treatment of trigeminal neuralgia. Arch Neurol 1985; 42: 801-802.

5. Morley TP, Barr HW. Giant intracranial aneurysms: diagnosis, course, and management. Clin Neurosurg 1969; 16: 73-94.

6. Hugenholtz H, Morley TP. The results of proximal anterior cerebral artery occlusion for anterior communicating aneurysms. J Neurosurg 1972; 37: 65-70.

7. Morley TP, Wortzman G. The importance of the lateral extensions of the sphenoid sinus in post-traumatic cerebrospinal thinorrhea and meningitis: clinical and radiological aspects. J Neurosurg 1965; 22: 326-332.

8. Morely TP. (editor) Current Controversies in Neurosurgery. Philadelphia: Saunders 1976.

9. Morley TP. Neurosurgical training in Canada. Neurosurgery 1977; 1: 161-167.

10. Morley TP. Some professional and political events in Canadian neurosurgery. Can J Neurol Sci 1985; 12: 230-235.

11. Lougheed WM, Tom M. Method of introducing blood into the subarachnoid space in the region of the circle of Willis in dogs. Can J Surg 1961; 4: 329-337.

12. Khodadad G, Lougheed WM. Repair of small arteries with contact cement and teflon graft. J Neurosurg 1964; 21: 552-560.

13. Khodadad G, Lougheed WM. Stapling technique in segmental vein autografts and end-to-end anastomosis of small vessels in dogs. Utilization of the operating microscope. J Neurosurg 1966; 24 : 855-864.

14. Khodadad G, Lougheed WM. Repair and replacement of small arteries, microsuture technique. J Neurosurg 1966; 24: 61-69.

15. Lougheed WM, Khodadad G. A new clip for surgery of intracranial and small blood vessels. J Neurosurg 1965; 22: 397-398.

16. Lougheed WM, Marshall B. The diploscope in intracranial aneurysm surgery: results in 40 patients. Can J Surg 1969; 12 : $75-82$.

17. Lougheed WM, Marshall BM, Hunter KM, Michel ER, SandwithSmyth $H$. Common carotid to intracranial internal carotid bypass venous graft. Technical note. J Neurosurg 1971; 34: 114 118.

18. Lougheed WM, Elgie RG, Barnett HJM. The results of surgical management of extracranial internal carotid artery occlusion and stenosis. Can Med Assoc J 1966; 95: 1279-1293.

19. Findlay JM. William M. Lougheed and the development of vascular neurosurgery at Toronto General Hospital. Can J Neurol Sci 1993; 20: 337-340.

20. Tasker RR. Percutaneous cordotomy - the lateral high cervical technique. In: Schmidek $\mathrm{HH}$ and Sweet WH, eds. Operative Neurosurgical Techniques. Indications, Methods and Results. New York: Grune \& Stratton, 1982: 1137-1153.

21. Tasker RR. The Thalamus and Midbrain of Man: A Physiological Atlas Using Electrical Stimulation. CC Thomas, Springfield, 1982.

22. Wherrett JR. In Memoriam: John Clifford Richardson (19091986). Can J Neurol Sci 1986; 13: 292-293.

23. Barnett HJ, Botterell EH, Jousse AT, Wynn-Jones M. Progressive myelopathy as a sequel to traumatic paraplegia. Brain 1966; 89: 159-174.

24. Baxter DW, Buettner-Enneer JA, Sharpe JA, Leigh RJ. Jerzy Olszewski: cartographer of the brainstem reticular formation. Neurology 1987; 37: 1881-1882.

25. Speical Notice: statement to medical publications from the Toronto General Hospital on the treatment of spinal cord injuries. J Neurosurg March 1968 (Inside front cover, no page number).

26. Tator $\mathrm{CH}$. New division of neurosurgery at Toronto Hospital. Surg Neurol 1991; 3: 378-379.

27. Morley TP. (editor) The Opening of the Neurosurgical Unit Toronto General Hospital November 8, 1958. University of Toronto Press 1960 page 33, Toronto. 